\title{
Saccharomyces cerevisiae live cells stimulate degradation and fermentation of cellulose by the rumen anaerobic fungus Neocallimastix frontalis MCH3.
}

\author{
F Chaucheyras 1,2, G Fonty 1, G Bertin 2, P Gouet 1 \\ IINRA, Laboratoire de Microbiologie, Theix, 63122 St-Genes-Champanelle; ${ }^{2 S a n t e l-g r o u p e ~ A g r i t e k, ~}$ \\ 85 rue Anatole France, 92300 Levallois-Perret, France
}

Some live micro-organisms such as Saccharomyces cerevisiae or Aspergillus oryzae are commonly used as feed additives (probiotics) in order to improve ruminant performances and health. With certain diets, they are known to have beneficial effects on digestibility, to alter fermentation patterns and to increase numbers of rumen bacteria, especially cellulolytic species (Wallace and Newbold, 1992, Probiotics : the scientific basis, Fuller R Ed, Chapman and Hall, London, 317353).

The effects of a Saccharomyces cerevisiae strain (SC) were investigated, in vitro, on degradation and fermentation of cellulose by an anaerobic fungus, Neocallimastix frontalis $\mathrm{MCH} 3$, which is particularly efficient on plant cell wall degradation (Bernalier et al, 1992, Curr Microbiol, 25, 145-148).
The addition of $10^{6}$ to $10^{7}$ live SC cells to fungal zoospores, in a vitamin-deficient medium, stimulated cellulose breakdown and fermentation end products concentration. Stimulation was dependent on the concentration of yeast cells added and their viability. At the early stages of fungal development, dry matter disappearance was greater in the vitamin-depleted medium in the presence of SC than that measured in the non deficient medium, indicating that $\mathrm{SC}$ increased the rate of cellulolysis. SC provided vitamins to $N$. frontalis, especially thiamine, which is found in yeast cells in high concentrations, and which is essential to fungal growth.

Live SC are able to stimulate plant cell wall degradation by the fungi, and could therefore enhance forage digestibility in the rumen.

$\begin{array}{lc}\mathrm{DM} \text { (cellulose) disappearance (\%) } & 2 \text { days } \\ \mathrm{MCH} 3 & 3.69 \pm 0.4 \\ \mathrm{MCH} 3+\mathrm{SC} & 20.34 \pm 1.23\end{array}$

4 days

$$
\begin{gathered}
9.79 \pm 0.48 \\
41.96 \pm 3.14
\end{gathered}
$$

6 days

$$
17.70 \pm 2.62
$$$$
45.50 \pm 2.44
$$

Fermentation end products ( $\mathrm{mM}$ ) after 6 days of incubation

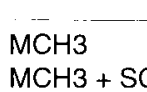

Formate
$3.9 \pm 0.2$
$12.1 \pm 0.2$

Acetate
$2.9 \pm 0.3$
$6.6 \pm 0.4$ Hydrogen

$3.7 \pm 0.2$

$7.7 \pm 0.7$ 